\title{
Prediction of the Geomechanical State of the Fixed Ground Basis of a Mining Building
}

\author{
Mikhail Sokolov ${ }^{1, *}$, and Mikhail Karablin² \\ ${ }^{1}$ T.F. Gorbachev Kuzbass State Technical University, Kemerovo, Russian Federation \\ ${ }^{2}$ Kuzbass Head Institute on designing of coal mining and coal processing enterprises (OAO \\ "KuzbassGhiproShakht"), Kemerovo, Russian Federation
}

\begin{abstract}
The results of engineering and geological surveys to the ground base of a mining and technical building, composed of man-made filled-up ground, are presented. A simulation of the stress-strain state of a fixed ground base was carried out. The analysis of changes in the geomechanical state of the ground massif as a result of injection compaction is presented, on the basis of which recommendations are given on adjusting the parameters of the injection technology.
\end{abstract}

\section{Introduction}

At working on the development and mining of mineral resources, specific attention is paid to technological safety issues, including non-emergency exploitation of buildings and structures. Mining buildings and facilities are most responsible objects that are subject to various types of negative factors, including the dynamic effects from traffic of mining machine and mass explosions. Separate categories of buildings and structures can be located on bulk ground bases from overburden and technogenic sediments with constantly changing hydrogeological regime. As a result of the impact of the combination of these factors, ground bases are subject to the formation of weak and water-saturated zones with low deformation and strength properties. To increase the stability of ground bases various methods of fixing are used, of which the methods of pressure injection and electrochemical fixing are widespread [1-4].

Along with the development of methods for fixing of ground bases, the issue of determining rational ranges of their technological parameters is topical. Existing analytical methods quite accurately determine the parameters of fixing, however, they do not take into account the structural heterogeneity of the massif, are based on empirical dependencies and have limited ranges of physical and mechanical properties [5-7]. More accurate parameters are obtained when integrating numerical modeling and forecasting methods based on basic and local models which are able to take into account the structural features of ground base, the presence of anomalous zones with low physic mechanical properties [8-10].

\footnotetext{
* Corresponding author: $\underline{\text { smv.ad@ } @ \text { kuzstu.ru }}$
} 


\section{Research methods}

An example of the manifestation of instability in the mining industry of Kuzbass is a building with an electro centralization post located in the territory of a coal mine. The examined building is a two-story brick building measuring dimensions in the plan $33.4 \times 12.4 \mathrm{~m}$ and height $10.7 \mathrm{~m}$ from the ground surface. The foundation of the building refers to a small foundation on a loose base and is made in the form of a continuous ribbon from foundation blocks. The assigned foundation depth in the project is $3.2 \mathrm{~m}$.

The study site has a complex relief and is characterized by a large number of slopes. The absolute marks of the relief are in the range of $255.1 \ldots 268.2 \mathrm{~m}$. The mine workings are located near the object, and in the northern and eastern parts there are various extensions and pre-fabricated frame structures (Fig. 1).

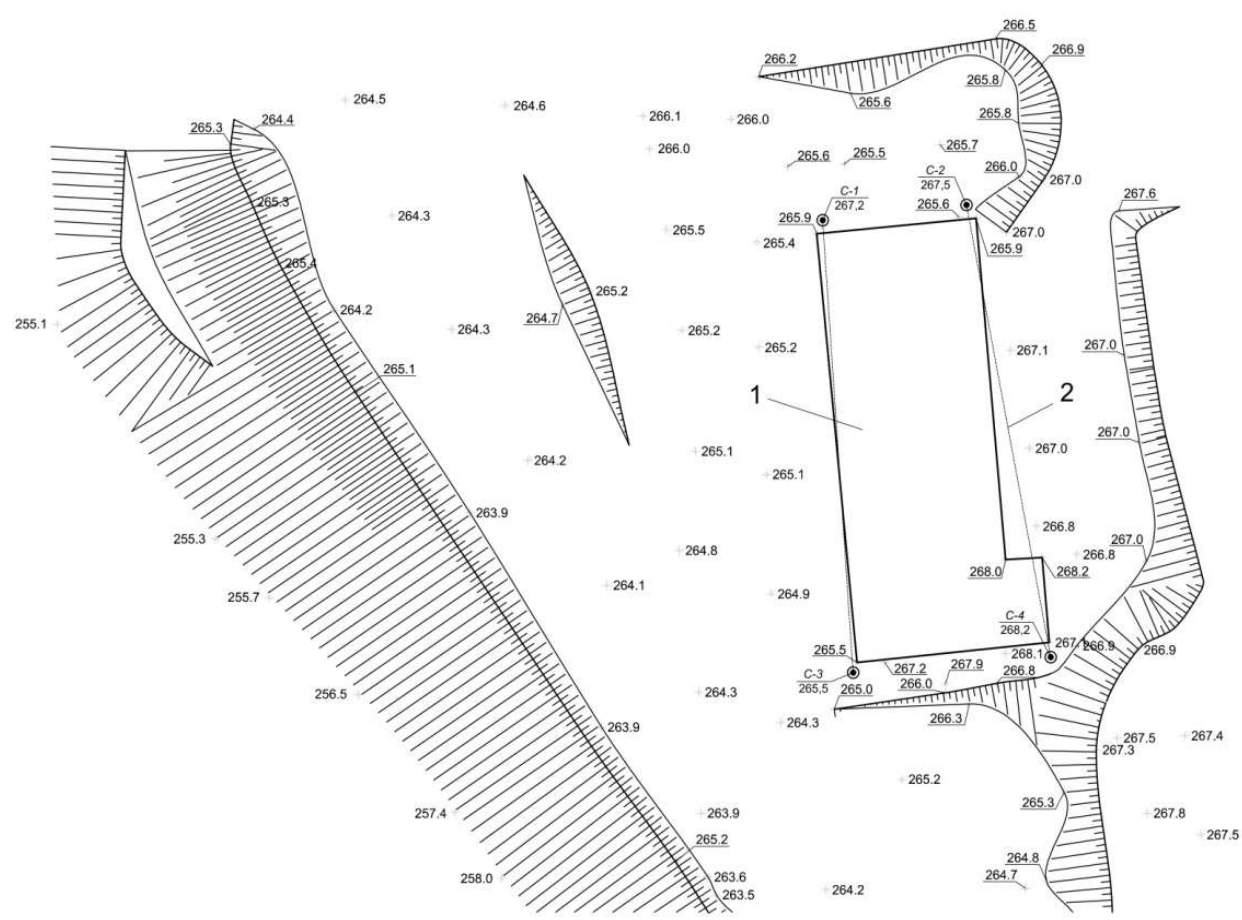

Fig. 1. Plan of the experimental plot: 1 - the surveyed building; 2 - lines of engineering geological sections; C-1 ... C-4 - engineering geological wells.

The ground base of the building is man-made sediments composed of overburden rocks - mining waste, represented by several soil types grouped by engineering geological elements (IGE).

IGE \# 1 - bulk soil, dark brown, in the form of a mixture of wood and crushed stone with loamy aggregate up to $25 \%$, from solid to "tugoplastichnoy" consistency, in uncompacted condition, was frozen in winter. The starting material is siltstone. The thickness of the layer ranges from $0.4 \mathrm{~m}$ to $1.9 \mathrm{~m}$.

IGE \# 2 - bulk soil, dark grey, in the form of a mixture of wood and crushed stone with loamy aggregate up to $15 \%$, in solid consistency, in uncompacted condition. The source material is mainly fine-grained, low-strength, highly weathered sandstone. The thickness of the layer ranges from $1.6 \mathrm{~m}$ to $6.1 \mathrm{~m}$.

IGE \# 3 - bulk soil, variegated, in the form of a mixture of wood and crushed stone with loamy aggregate up to $23 \%$, in solid consistency, in compacted and packed condition. The 
starting material is siltstone, argillite, and "burnt rock". The thickness of the layer ranges from $2.2 \mathrm{~m}$ to $2.4 \mathrm{~m}$.

IGE \# 2 has a distinctive feature in the form of a wedge-shaped occurrence with falling in two planes in accordance with the above engineering-geological sections (Fig. 2).
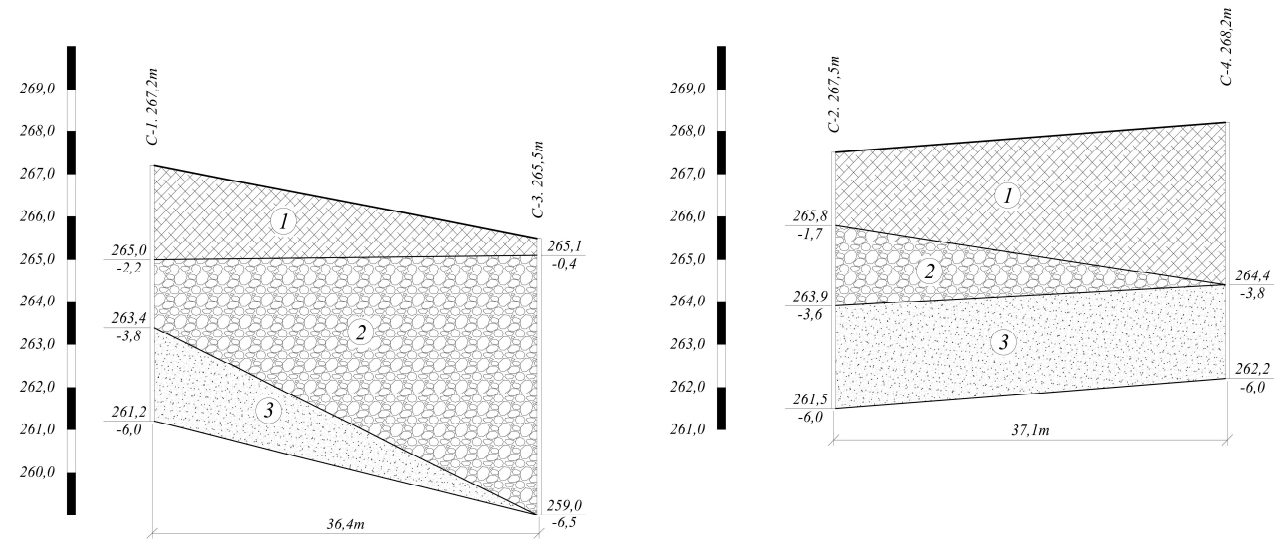

Fig. 2. Engineering geological sections: 1 ... 3 -numbers of engineering geological elements.

The main physic and mechanical properties were determined under laboratory conditions and are shown in Table 1.

Table 1. Summary table of soils mechanical properties.

\begin{tabular}{|c|c|c|c|c|c|}
\hline & \multirow{2}{*}{$\begin{array}{c}\text { The name of the physic and } \\
\text { mechanical properties }\end{array}$} & \multirow{2}{*}{ Units } & \multicolumn{3}{|c|}{$\begin{array}{c}\text { The number of engineering } \\
\text { geological element }\end{array}$} \\
\hline & & & IGE \#1 & IGE \#2 & $\begin{array}{c}\text { IGE } \\
\# 3\end{array}$ \\
\hline 1 & $\begin{array}{l}\text { Natural density } \rho \text { : } \\
\quad \text { - in natural state } \\
\text { - in wetted state }\end{array}$ & $\mathrm{g} / \mathrm{cm}^{3}$ & $\begin{array}{c}1.65 \\
-\end{array}$ & $\begin{array}{l}1.95 \\
1.75\end{array}$ & $\begin{array}{l}2.05 \\
1.95\end{array}$ \\
\hline 2 & $\begin{array}{l}\text { Angle of internal friction } \varphi \text { : } \\
\quad \text { - in natural state } \\
\text { - in wetted state }\end{array}$ & deg. & $\begin{array}{c}20 \\
-\end{array}$ & $\begin{array}{l}24 \\
20\end{array}$ & $\begin{array}{l}31 \\
24\end{array}$ \\
\hline 3 & $\begin{array}{l}\text { Coupling } C \text { : } \\
\quad \text { - in natural state } \\
\quad \text { - in wetted state }\end{array}$ & $\mathrm{kPa}$ & $\begin{array}{l}7 \\
-\end{array}$ & $\begin{array}{l}19 \\
10\end{array}$ & $\begin{array}{l}28 \\
25\end{array}$ \\
\hline 4 & $\begin{array}{l}\text { Deformation module } E \text { : } \\
\quad \text { - in natural state } \\
\quad \text { - in wetted state }\end{array}$ & $\mathrm{MPa}$ & $\begin{array}{c}10 \\
-\end{array}$ & $\begin{array}{l}20 \\
12\end{array}$ & $\begin{array}{l}24 \\
20\end{array}$ \\
\hline
\end{tabular}

As part of the work, computer geomechanical modeling was carried out on the basis of the Alterra software package of the Russian developer InzhProjectStroy. The study of changes in the geomechanical state is based on local models of ground base, implemented with using the finite element method [11-13], in zone with the most characteristic form of bedding (Fig. 3, $a$ ).

The model has a basic sizes of $38 \times 18.2 \mathrm{~m}$, includes 3 layers of technogenic deposits according to the presented sections and 3 band foundations at a distance of $6 \mathrm{~m}$ from each other. Each foundation is loaded with a concentrated force $P$ and transmitting force to the sole $1.2 \mathrm{~m}$ wide, located at a depth of $d_{f}=3.2 \mathrm{~m}$. The foundations are made of reinforced concrete with the following properties: density $\rho_{f}=2500 \mathrm{~kg} / \mathrm{m}^{3}$, deformation module $E_{f}=$ $2000 \mathrm{kPa}$, Poisson's ratio $v=0,15$. The physic mechanical properties of IGE are taken as for the wetted state, which simulates a change in the hydrogeological mode. The model has 
limitations and boundary conditions for lateral and lower boundaries [14]. The calculation was performed in the linear-plastic stage with a task of no more than 500 iterations for nonlinear deformation and no more than 500 iterations for plastic shear deformations [15].
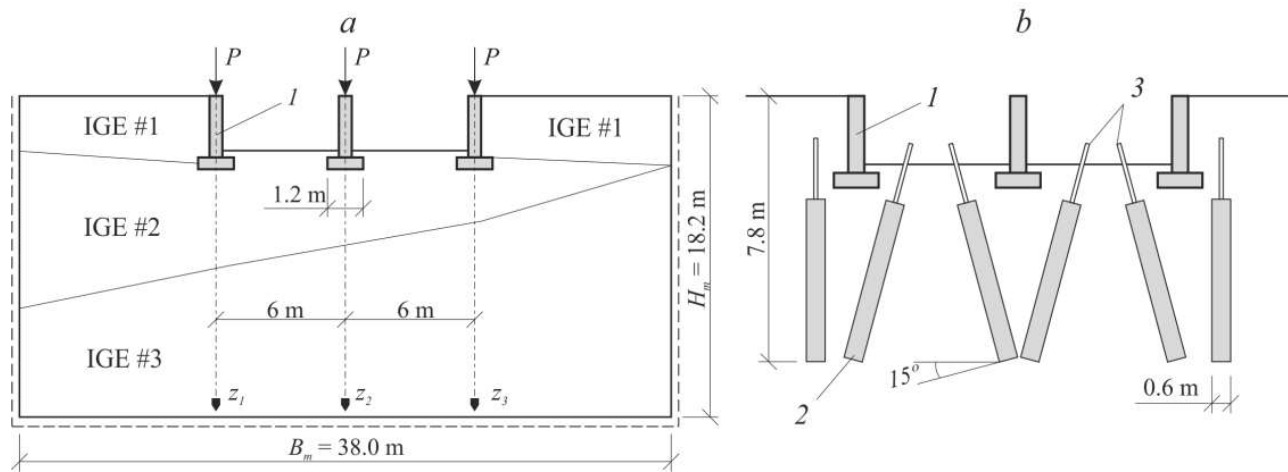

Fig. 3. Schemes of the local model and fixing of the ground base: 1 - the ground base; 2 - fixing zone; 3 - injectors.

To study the effect of fixing the ground base by pressure injection of cement-sand mortars, a scheme was adopted for fixing the base for a building on band foundations with internal load-bearing walls. The depth of immersion of the injectors, their location and the parameters of the pressure injection were taken according to the project of OOO NooCenter (Fig. 3, b).

\section{Results}

The results were analyzed along the characteristic vertical axes $z_{1}, z_{2}$, and $z_{3}$ located along the axes of symmetry of each foundations.

Primary simulation results in the form of graphs of vertical $\sigma_{z}$ and horizontal $\sigma_{x}$ stresses are presented in Fig. 4.

The graphs of vertical stresses $\sigma_{z}$ monotonously decrease with increasing depth of the massif, and their magnitude decreases with the introduction of zone of fixing into the calculation. Not characteristic is the area of stabilization of stresses $\sigma_{z}$ in the interval $z_{2}=$ $=5.5 \ldots 10.0 \mathrm{~m}$. Horizontal stresses $\sigma_{x}$ along the $z_{l}$ axis are distributed with the formation of a zone of minimum values in the interval $z_{l}=5.0 \ldots 7.5 \mathrm{~m}$. However, the stresses $\sigma_{x}$ along the $z_{2}$ and $z_{3}$ axes are distributed only within the limits of IGE \# 2, also at a fixing massif along the boundary of layers 2 and 3 negative values of stresses are formed.

The second stage of the analysis aims to assess the regularities of the total $\varepsilon_{z}$ and plastic $\varepsilon_{z p}$ vertical deformations shown in Fig. 5.

The deformations of $\varepsilon_{z}$ along the $z_{l}$ axis have similar outlines with stress graphs, with the exception of the peak of deformations in the interval $z_{1}=4.0 \ldots 5.0 \mathrm{~m}$, which is retained in fixing massif, but has a smaller amplitude. Along the $z_{2}$ axis, the $\varepsilon_{z}$ deformations are distinguished by a pronounced drop in the values at the boundary of the layers IGE \# 2 and \# 3, which is not eliminated in fixing massif. On the interval $z_{2}=3.8 \ldots 4.9 \mathrm{~m}$, the values of $\varepsilon z$ increase significantly. The presence of "a jump" of the deformations at the boundary of the layers is also characterized by the $\varepsilon_{z}\left(z_{3}\right)$ graph, beyond which the calculated values monotonously decrease.

The manifestation of plastic deformations $\varepsilon_{z p}$ is characteristic only at a depth of up to $6 \mathrm{~m}$, only within the limits of IGE \# 2 (of a weak, not packed layer), with it's the distribution graphs along all axes have a area of maximum. When fixing, the greatest effect is observed for the $z_{l}$ and $z_{3}$ axes, where the $\varepsilon_{z p}$ values decrease by 2 and 1.5 times, respectively. 

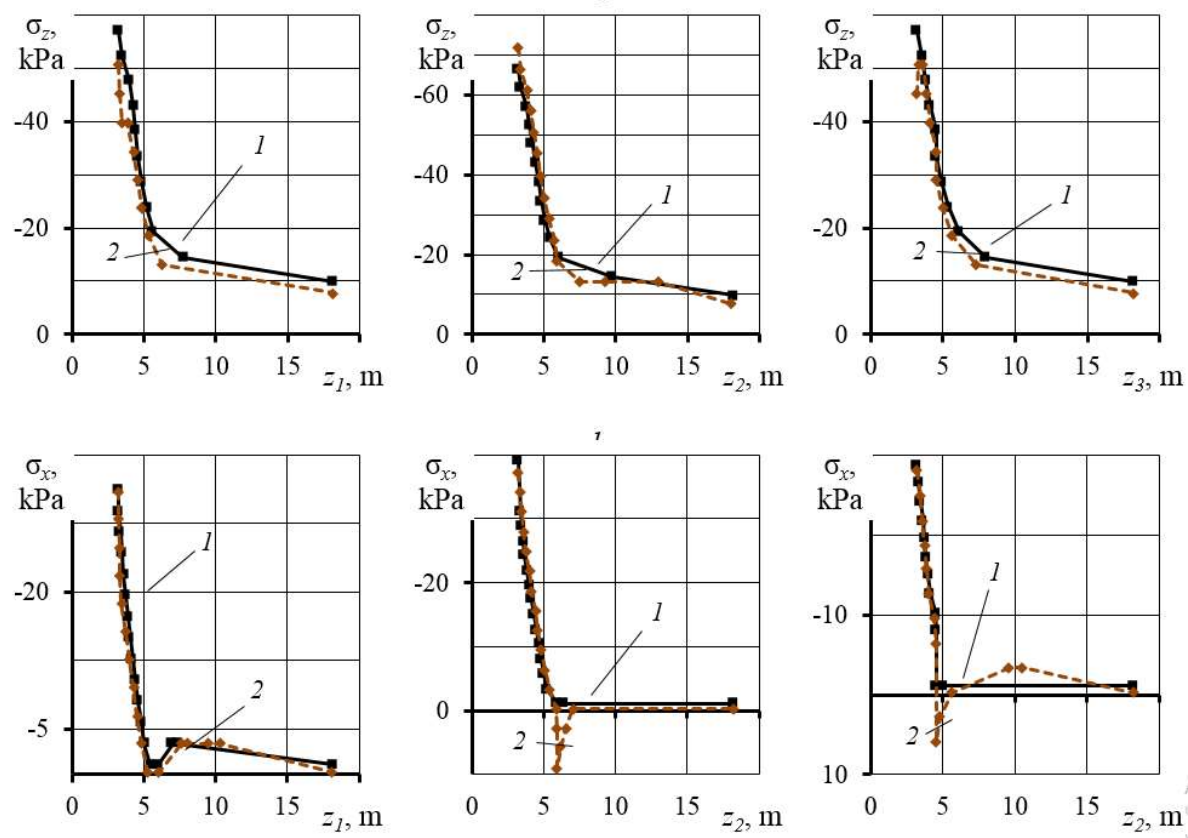

Fig. 4. Dependence of vertical $\sigma_{z}(a)$ and horizontal $\sigma_{x}(b)$ stresses from the depth of the model $z$, with: 1 - the natural massif; 2 - the fixed massif.
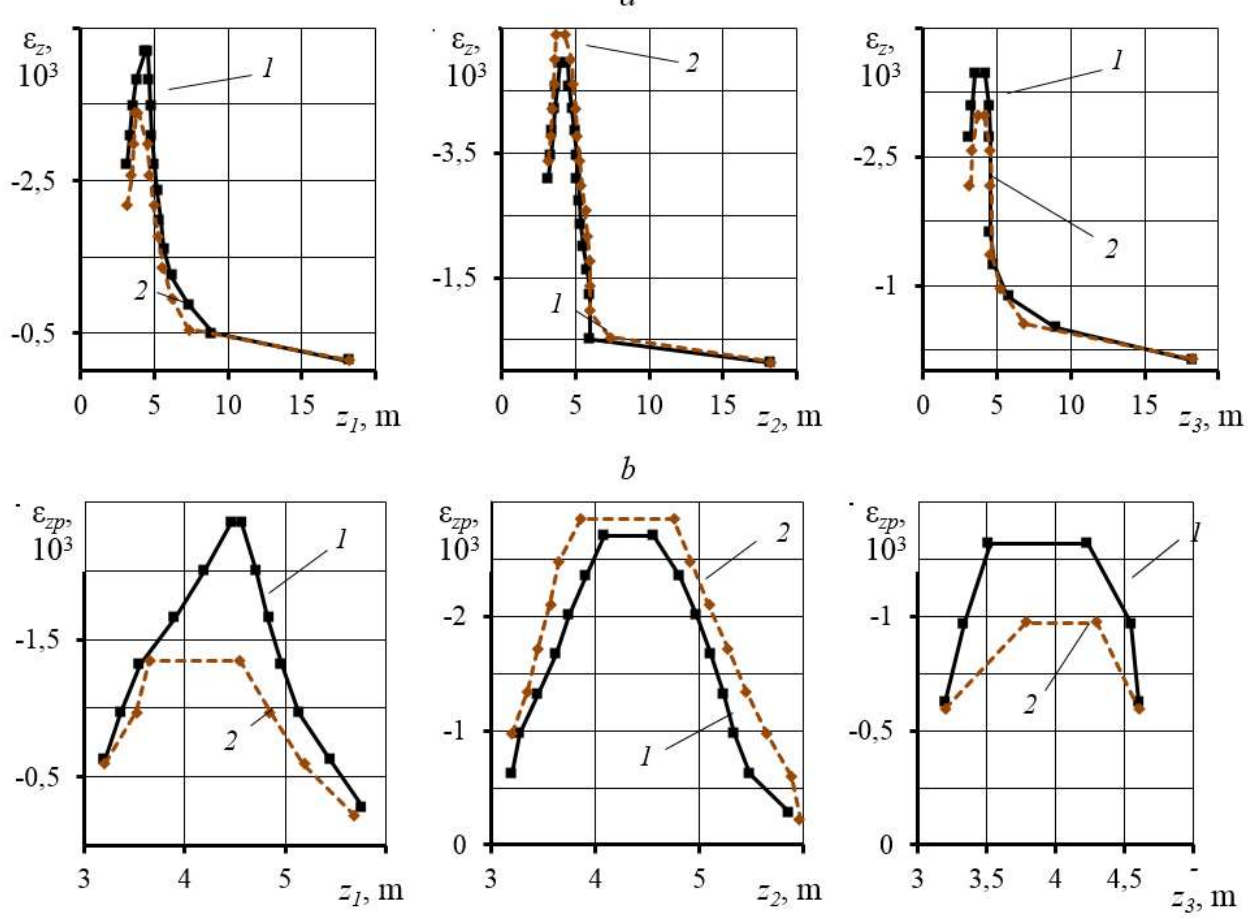

Fig. 5. Dependence of the full $\varepsilon_{z}(a)$ and plastic $\varepsilon_{z p}(b)$ vertical deformations from the depth of the model $z$, with: 1 - the natural massif; 2 - the fixed massif. 
The negative is the increase in deformations $\varepsilon_{z p}$ along the $z_{2}$ axis by an average of $14 \%$, with an increase of the zone of plastic deformations by $0.2 \mathrm{~m}$ in depth. Thus, the results of the evaluation of the deformed state indicate a lack of effectiveness of the adopted fixing scheme for the central foundation.

\section{Conclusion}

According to the results of the analysis the effectiveness of the fixing of the ground bases was generally confirmed, manifested in the form of a significant decrease in vertical deformations and stresses. Identified the need to change the scheme of fixing of the central foundation, because along the $z_{2}$ axis both complete and plastic deformations increase, and horizontal stresses have negative values at the interface of layers 2 and 3 . With regards to the foundation along the $z_{3}$ axis, an assumption was made about the possible displacement of the inclined fixing zone under the action of loads. Due to the increased rigidity and the presence of a metal injector in the zone of fixing, the cut across the cross section is not considered.

Based on the results of geomechanical modeling, it is recommended to change the scheme of fixing the central foundation from inclined to the vertical location of the wells.

Thus, an increase in time without emergency operation of buildings during mining operations will be achieved.

\section{References}

1. M. N. Ibragimov, Soil Mech. Foun. Engin., 50, 200 (2013)

2. M. N. Ibragimov, Soil Mech. Foun. Engin., 52, 100 (2015)

3. Shao-Chi Chien, Fu-Chen Teng, Chang-Yu Ou, Acta Geotech., 10, 813 (2015)

4. Flora, S. Gargano, S. Lirer, L. Mele, Geotech. Geolog. Engin., 9, 650 (2017)

5. S. M. Prostov, N. Yu. Nikulin, J. of Mining Science, 51, 908 (2015)

6. V. Azarov, M. V. Kurlenya, A. V. Patutin, S. V. Serdyukov, J. Min. Sci., 51, 1063 (2015)

7. T. V. Lobanova, S. V. Moiseev, J. Min. Sci., 45, 227 (2009)

8. G. Protosenya, M. A. Karasev, Soil Mech. Foun., 51, 53 (2014)

9. L. A. Strokova, Soil Mech. Foun. Engin., 46, 117 (2009)

10. D. Mujah, K. S. Siaw, S. Tasnim, Soil Mech. Foun. Engin., 52, 317 (2016)

11. S. G. Bezvolev, Soil Mech. Foun. Engin., 45, 77 (2008)

12. Z. G. Ter-Martirosyan, A. S. Abdulmalek, Soil Mech. Foun. Engin., 44, 195 (2007)

13. D. M. Shapiro, N. N. Mel'nichuk, Soil Mech. Foun. Engin., 44, 62 (2007)

14. S. M. Prostov, M. V. Sokolov, Taishan Acad. Forum - Project Min. Dis. Prev. Cont., 350, 122 (2014)

15. S. M. Prostov, M. V. Sokolov A. V. Pokatilov, Inter. J. Ap. Eng. Res., 10, 45297 (2015) 